\title{
An analysis of learners' intentions toward virtual reality online learning systems: a case study in Taiwan
}

\author{
Yi-Ting Wang \\ Ling Tung University \\ w7yw7k@gmail.com
}

\author{
Kuan-Yu Lin \\ Ling Tung University \\ ntustmislab@gmail.com
}

\author{
Travis K. Huang \\ Ling Tung University \\ travisk.huang@gmail.com
}

\begin{abstract}
The virtual reality technology, VR, features feeling of blending in, interactivity and imagination. It not only improves on the limitations of conventional learning methods but also enhances the communication of learning contents and messages via interactivity and imitation. Over the past decade, the incorporation of information technology in education has been an important research topic. Following the computer-aided teaching, interactive online learning, distance teaching and mobile learning of the earlier days, the VR technology is now regarded as a new wave of trend facilitating the incorporation of application technology into education.

To explore the factors that affect users' use of virtual reality online learning systems (VROLS), this study based on the theory of cost-benefit perspective and incorporating the perceived value and the flow theories proposes an integrated research model elaborating on why people opt for VROLS services. A total of 296 valid samples were collected from online questionnaires and the data were analyzed using the structural equation modeling (SEM) approach. The findings suggest that both perceived value and flow experience are important roles in users' use of VROLS services, in which benefits (spatial presence, enjoyment, service compatibility) and costs (complexity and visual fatigue) are the critical factors affecting users' perceived value and flow experience. The implications of these findings are further discussed.
\end{abstract}

\section{Introduction}

Amid the development of information technology and mature infrastructure of network communications, multimedia technologies of all kinds, e.g., PCs and mobile devices, began to widely penetrate aspects of people's living. Besides satisfaction in terms of the looks and the functions, people also began to look for information technology (such as virtual reality, VR) that makes them feel really being in certain environments. VR, by means of simulated screens and related interactions [1], provides users with special experience that breaks through temporal and spatial limitations. VR had been widely applied in the entertainment business, but, as the technology becomes more mature with costs reduced, VR technology is no longer subject to the limitations of equipment, like headsets, server efficacy and device expenses. It is now applied by corporations in various fields, such as education, medicine, architecture, manufacturing, travel, and retail sales. It shows particular and strong potential in educational applications. VR not only improves on the limitations of conventional teaching environment, its virtual interactions and photorealistic feature also enhance the communication of content information of education and training [2][3] and assist learners in better understanding curricular contents, increasing learning effectiveness [2][4]. That shows VR technology is at present a most exciting trend of applications of teaching technology.

With the VR technology for teaching, design of contextual teaching can be made to simulate practical contexts [3] because this technology can provide presence, amusement, effect of flow, exploration, dynamic interaction and the feature of instant visual feedback [2][4]), while being able to provide learning models that are learner centered to facilitate their exploration in learning [2][4]. As such, in education, the VR technology not only enhances the pleasure of learning and makes abstract knowledge and concepts concrete to facilitate students to learn by appropriately making learning like playing to break the spatial limitation of classroom for teachers and students and by challenges in the playing to allow students to practice the play, but also increases the students' learning intention. The findings of the study by Zhang et al. [4] suggested that through the VR technology, learners can do self-oriented and active learning more easily, while their learning intention is enhanced, and in turn their learning effectiveness is increased. Hence, for VR service providers, understanding what affect learners' intention to use VR online learning to achieve their learning effectiveness is an important issue for this study to explore.

The recent research in emerging technologies (e.g., VR, AR, mobile technology and social network 
sites) tended to incorporate the value view in the research context, where perceived value was one of the key issues. A number of researchers [5][6][7] also stated, from the cost-benefit perspective, that when users compare the benefit of using a service or product and the cost they need to pay, a perceived value forms in their mind, which in turn affects their usage intention. For users, to use an emerging information technology is often subject to whether there is a balance between the factors of their perceived benefit and those of the perceived cost in order to verify their perception of value, and in turn to affect their embracement and usage of such technology [7][8][9].

In addition, according to researchers [1][10], while the utilitarian aspect of the simulated environment with the VR technology needs to be taken into account, the pleasurable factor is also among the key aspects. With regard to $\mathrm{VR}$, the pleasant experience is a state that occurs most often when users are experiencing the VR devices [10][11]. When exploring users' pleasurable experience, prior research applied the flow theory a lot [10][11][12]. Proposed by Csikszentmihalyi [13], the Flow Theory says that flow experiences are a pleasurable one, in which people are totally immersed in the activities they are engaged in, more concentrated; that is an experience full of pleased mind, which, if without incentives, still attracts people to personally feel it again. A lot of research [12][14] informed that flow experience forms in individuals whose feeling of value is increased, and in turn they continue to use the information system; that is, the relationship between users' perceived value of the information technology and their usage intention is affected by the intermediate effect of flow experience. In such view, this study proposes, based on the costbenefit and the perceived value theories, further with the factors of intermediate effect of flow experience, an integrated research model, whereby to explore the factors affecting learners' behaviors of use of VR applied in online learning contexts. This study answered the following research questions (RQs):

RQ1. What are the cost-benefit characteristics of VROLS factored into perceived value and flow experience?

RQ2. What is the key factor influencing learners' intention to use VROLS?

\section{Literature review}

\subsection{Cost-benefit theory}

According to the cost-benefit theory, people who are making decisions consider the benefits from their acts and the costs they need to pay, and they tend to resort to decisions with maximal benefit and minimal cost [7][8]. A number of research [5][8][9] indicated that when users are to make action decisions, they take into account the (monetary and non-monetary) costs they need to pay when using, and when they have compared the benefits and the costs, there would be perceived value for the service or product, while the feeling of value would affect their intention to use the service or product. In this study, we consider that when users are doing online learning with VR, and when having compared the benefits and costs, it would affect their feeling of value, which in turn enhances their usage behaviors. In this view, this study extends the research model based on the cost-benefit theory to explore the effect on people's perceived value of learning with VR.

\subsection{Perceived value}

The value in the customer's mind is formed as a result of the process of cognitive comparison, which is an evaluation of the benefit of a product or service as a whole [5]. Perceived value has direct and significant effect on customers' intention of behavior [7][8][9]. The comprising elements of perceived value differ with customers, where the most common way of defining value is the ratio of quality to price. Yet, as stated by certain researchers, it is too simplified to think value as the measurement based on quality vs. price [15], where weighing the customer's whole value by one single measure will lack validity [5][6][9], also will fail to reflect what was commonly believed in the literature as "the perceived value is a replacement relationship between give and take".

Following that, researchers [5][6] extended, in the cost-benefit perspective, the constructs of measurement of perceived value according to the contexts of research. Kim et al. [5] measured perceived value in terms of perceived utility, perceived hedonism, technological usability and perceived costs to explore the effect on users' usage intention of mobile networks. Their findings were that of users' perceived usability, hedonism, every of the technological usability and cognition of costs, all significantly affect perceived value and that the latter further significantly affects users' behavior intention. Lin and Lu [6] explored the effect on users' perceived value of mobile technology in terms of mobile convenience, service compatibility, safety risks and perceived efforts; they discovered that every of these four dimensions affects users' perceived value.

It is clear from the above that different dimensions of value in various situations of decision, products and services affect users' decisions. Values are a sustained confidence, based on which the individuals prefer certain kinds of ways of behavior or living style [6][9]. A lot of research reported that perceived value has direct and significant effect on customers' behavioral intention $[5][6][7][9]$. Therefore, this study will 
examine, in the research context with VR applied to learning contexts, the effect of users' perceived value of VR on their behavioral intention of online learning.

\subsection{Flow theory}

Csikszentmihalyi [13] believed that when people are so intensively concentrated on the status of a certain activity that they ignore all other things around, a Flow Experience is present, which in turn affects their usage intention. He further stated that the flow is a state of people strongly focused on a certain activity, where no other things seem important, because people feel such activity so much fun that they can engage in it at any cost [16], which in turn affects their usage behavior. In an individual who is engaged in a certain activity out of curiosity, he/she feels a totally involved and intense pleasure that leads to more explorations. Chang and Zhu, [17] argued that flow is a temporary and subjective experience and it also is the reason why people intend to continue to be engaged in a certain activity; that when people concentrate on certain activities and shut off other unimportant perceptions to be completely committed, they are in a flow.

The flow theory was first applied in research in living, work, sports, leisure and others, and in the recent years when the internet developed rapidly, researchers began to explore, based on the flow theory, topics of research, such as VR technology, AR mobile games, online learning, online games, online shopping and social networking [11][18][19][20]. In a virtual reality, the preview of the service environment by operating the system on a PC or mobile device allows the user to feel the presence of reality in it and enables $\mathrm{him} / \mathrm{her}$ to be in a flow experience in such VR environment. When the user has good experience, that may further his/her usage behavior [11][19]. Hence, flow experience is important to users' behaviors, as only when they are in a flow of VR-based online learning context, their learning intention is enhanced.

\section{Research model and hypotheses}

Figure 1 illustrates the proposed model, which is perceived value and related literature. The definition and hypothesis of each construct of the model are explicated in the following subsections.

\subsection{Perceived value}

As defined by Kim et al. [5], perceived values are "users' perception of information systems, where they take into account the costs and benefits behind their behaviors, as a process of assessment of entire utility". Research of recent years also indicated that users' inner feelings have positive effect on their behavior intention [5][6][7][8]. On the other hand, Kim and Thapa [14] discovered in their research that individuals' flow experience is affected by their perception of values. When an individual using information technology perceives value in it, that induces a feeling of total involvement, and in turn enhances the behaviors of use. From the above state, this study hypothesizes that if a learner who performs learning with VR thinks of the entire value brought about by incorporating VR technology in learning contexts as higher, that affects his/her flow experience and in turn enhances his/her behavior intention. Synthesizing the above scholarly perspectives, this study gives the following hypotheses:

[Hla] Perceived value positively affects learners' usage intention of VR-based online learning.

[HIb] Perceived value positively affects learners' flow experience.

\subsection{Flow experience}

Csikszentmihalyi [13] believed that the flow is an enjoyable experience and is used to measure the feelings of pleasure. In the research of why people feel happy, it was found that the flow is a happy experience, i.e., when people are engaged in certain activity, the existence of specific goal makes them clearly aware of what they are doing and enjoy in the process of achieving the goal [16]. As such, a definite goal is one of the conditions of forming flow experience. In learning, learning the knowledge and skills is an important goal. In many cases of use of information technology, it is accompanied by flow experience, which in turn affects the user's usage behavior [12][18]. In VR-related research, the researchers indicated that flow experience is the crucial factor affecting users' usage of VR technology. With VR, the user operates the system by using a PC or mobile device, where the experience of the service via imitated scenes allows the user to be immersed in the VR environment, and, when he/she has the flow experience, that facilitates his/her usage behavior [10]. This study deduces that if a learner who uses VR-based online learning system is able to have a flow experience in the learning activity, that would increase his/her usage intention. Thus, we hypothesize:

[H2] Flow experience positively affects learners' usage intention of VR-based online learning system.

\subsection{Benefits (Spatial present, Enjoyment, and Service compatibility) \\ Spatial present \\ Roger [21] referred to relative advantages as} whether a new product or service has better product attributes or product benefits; in other words, if a user considers an emerging technology has greater benefits than existed ones, he/she believes such information technology has relative advantages [6][9]. 


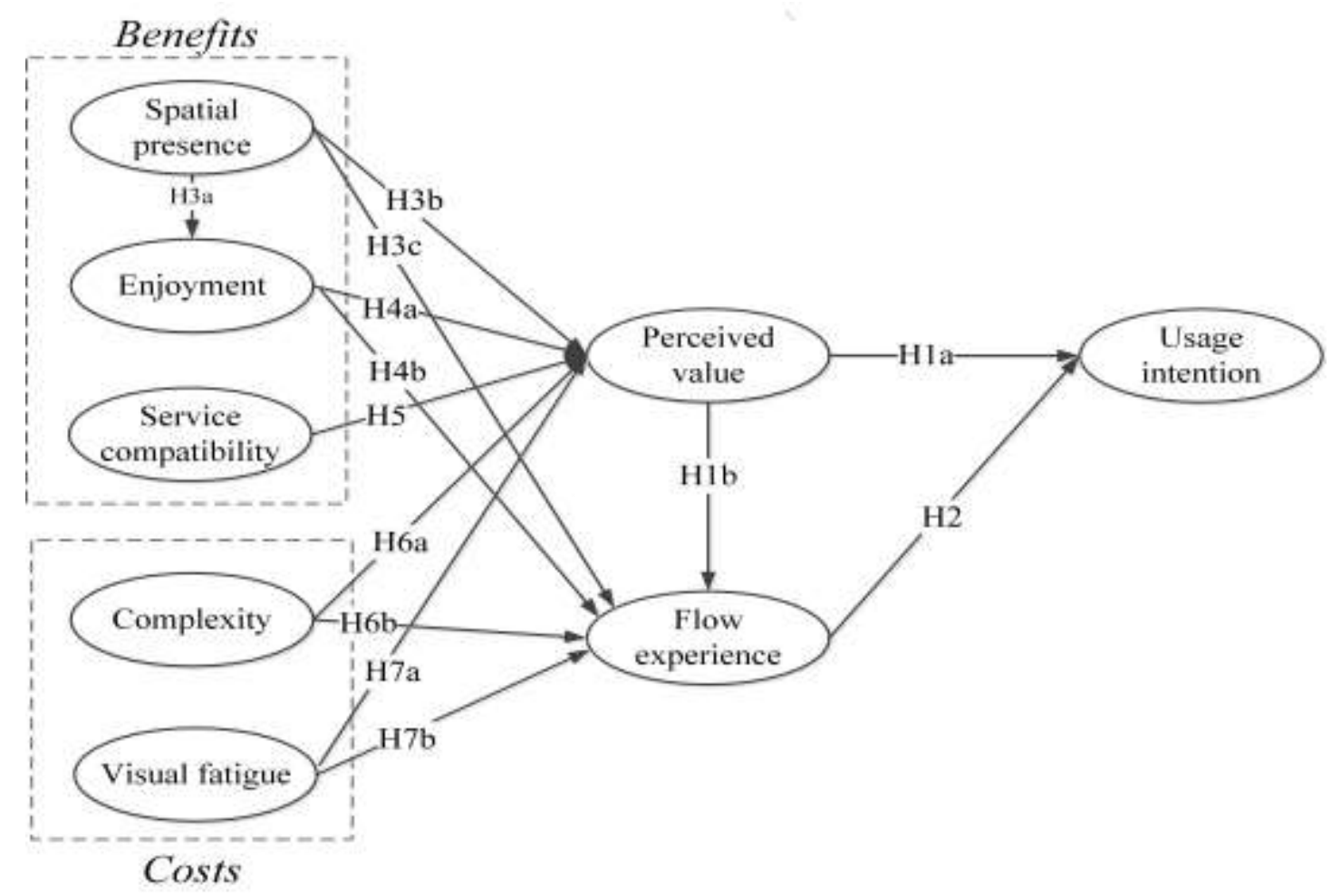

Figure 1. The research model

The greatest advantageous characteristic of VR technology is the provision of spatial presence [20][22] With the VR-based 3D spaces, users can view, in 360degree panorama, the contents of product and spatial environment, which allows them to feel as if they are really in a reality with their body sense, because the VR technology is able to bring about an as-real feeling of holistic virtual environment to the users, endowing them a flow experience. This study thus considers the use of VR technology can bring about a feeling of relative advantages to users (e.g., spatial presence). A number of researchers explored, with spatial presence in different contexts, the effects on users' intention to use information technology, and they discovered [22][23] that spatial presence positively affects enjoyment and in turn generates feeling of value, which affects users' behavior intention. As such, this study considers the characteristic of spatial presence in online learning that VR technology provides allows the user to have real feeling of learning in virtual environment, receive enjoyable feeling and increase their flow experience. Additionally, other researchers [11][20] reported that spatial presence affects users' flow experience. In a VR context, spatial presence is an important factor that directly affects users' flow experience [11]. This study thus hypothesizes as follows:
[H3a] Spatial presence positively affects the enjoyment of learners about VR-based online learning.

[H3b] Spatial presence positively affects learners' perceived value of VR-based online learning.

[H3c] Spatial presence positively affects learners' flow experience in VR-based online learning.

\section{Enjoyment}

Enjoyment is the pleasure an individual subjectively feels in taking certain behavior or performing certain activity [5][6], in other words, the user has inner pleasure during the use of information technology. Enjoyment is a positive attribute of VR technology [4][22]. Prior research [7][18] explored, with enjoyment in different contexts, the relationship between user's perceived value and flow experience. The findings were that the enjoyment brought about by information technology positively affects perceived value. Meantime, enjoyment is one of the key factors of flow experience, which Kim and Hall [10] testified as well. In a VR context, enjoyment positively affects user's flow experience. As VR is capable of providing spatial presence, amusement, exploration, dynamic interaction and instantaneous visual feedback of learning as complementary to online learning [2][4], it allows the users to experience the functions no past websites had provided, thus bringing about enjoyable 
experience to the users during their use. Synthesizing the above scholarly perspectives, this study hypothesizes as follows:

[H4a] Enjoyment positively affects learners' perceived value of VR-based online learning.

[H4b] Enjoyment positively affects learners' flow experience in VR-based online learning.

\section{Service compatibility}

In his framework for characteristics of innovations, Roger [21] defined compatibility as the consistence between innovations and potential users' existed values, past experiences and demands. What service compatibility emphasizes is the consistence between the services the information technology provides and the users' needs for service [6][9]. When incorporated in a learning context, the VR technology not only can improve on the limitations of conventional learning methods but also enhances, by means of the interactivity and imitative characteristic of VR, the training of learning contents and message transmission [2][3], to offer users the learning services through VR. In other words, when a user perceives of being able to learn with VR service like in real world contexts and to interact with the characters in the context just like using conventional teaching modes, he/she is able to satisfy his/her perceived value, which in turn enhances his/her usage behavior. Thus, we have the following hypothesis:

[H5] Service compatibility positively affects learners' perceived value of VR-based online learning.

\subsection{Costs (Complexity and Visual fatigue) Complexity}

Complexity is the need by an individual who is using an innovative technology or service to spend excessive time or effort to learn or use it [6][7]. In other words, that is perceived relative difficulty of a product or service to understand and use [21]. Complexity is widely applied to the exploration of use of emerging technological services or products [6]; for such a product of service, if the system interface is relatively difficult to operate, that would cause decrease in the user's satisfaction with the product and in turn has negative effect on his/her impression about the product or service [9]. As such, the difficulty in operating an information system creates negative effect for users and in turn makes them reluctant to use the emerging information technology [6][9]. Thus, this study considers that when a user operates a learning system on VR, if he/she needs to access multiple interfaces or operations in order to use the service, that would affect his/her perceived value of the system, also, the relative difficulty during the process of operation will deter the user from concentrate or commit him/herself, which will affect his/her flow in the learning activity, and in turn affects his/her usage behavior. As such, this study considers that complexity negatively affects user's perceived value of and flow experience in VR learning systems. Hence, we give the following research hypotheses:

[H6a] Complexity negatively affects learners' perceived value of VR-based online learning.

[H6b] Complexity negatively affects learners' flow experience in VR-based online learning.

\section{Visual fatigue}

Visual fatigue is a compromised function of human vision system, as a result of over-tiring to physical change or tension [24][25]. Prior research examined the effects from people's using technological products and visual fatigue, such as watching 3D videos [26], reading in LED light [27] and digital reading [28]. It was indicated that a technological product that causes visual fatigue in people would generate negative psychological reaction to it, which in turn decreases their usage intention. In VR-related research, some researchers explored the visual fatigues caused by VR, such as the effects of visual fatigues from using headset display, and how much the viewing directions and distances with 3D affect visual fatigues [29]. It was indicated that visual fatigues negatively affect users' psychological reaction. As such, this study assumes that if a learner who performs learning with VR feels visual fatigue, that negatively affects his/her perceived value of and flow experience. Thus, this study hypothesizes as follows:

[H7a] Visual fatigues negatively affect learners' perceived value of VR-based online learning.

[H7b] Visual fatigues negatively affect learners' flow experience in VR-based online learning.

\section{Research methods}

\subsection{Measures of the constructs}

To ensure content validity, the items selected for the constructs were largely adapted from prior research. The items were slightly modified to suit the context of VR online learning system (VROLS). All items were measured on a 5-point Likert-type scale, ranging from "strongly disagree" (1) to "strongly agree" (5). As the questionnaire was administered in Chinese, the translation-back translation procedure was employed, in which two bilingual (EnglishChinese) research assistants translated the original English questions used in various prior studies into Chinese to maintain translation equivalence. To address face validity, three professors were asked to refine the questionnaire. Based on their feedback, some items were reworded to fit the research purpose. The 
result of the pretest provided a first assurance of the validity of the scale items.

The survey questionnaire includes eight constructs. The items of spatial presence were modified form Kim and Ko [11] and Rodriguez-Ardura and Meseguer-Artola [20]. Measures of enjoyment were adapted from Kim et al. [5] and Wang et al. [7]. Service compatibility were adapted from Fang et al. [30] and Lin and Lu [6]. Complexity was modified from Fang et al. [30] and Kim and Ammeter [31], and items used to measure the visual fatigue were adapted from Cho et al. [32]. Perceived value was assessed based on the scale proposed by Kim et al. [5]. Items for measuring flow experience were developed from Chang and Zhu [17]. Finally, items measuring usage intention were modified form Wang et al. [33].

\subsection{Data collection and sampling}

Opinions from VR online learning system users were collected to test the proposed model. The target participants were users who were using or had used VR online learning system experience in Taiwan. Data were collected mainly through an online questionnaire survey. This method features the advantages of fast response, low cost and no geographical limitation to sources of sample [34]. Invitation messages were posted on popular forums associated with VR online learning system sites, such as Daydream walker (https://var.daydreamwalker.io/web/index.php), EdTech Taiwan (https://www.facebook.com/EdTechTW/), and So-easy (https://www.so-easy.com.tw/muvizu.html) over a six-week period. The contents of learning with the VROLS employed by the subjects were of great variety of categories from language, computer, mathematics to medicine, sciences and others. To avoid duplicate responses, respondent identity was confirmed by using the e-mail and IP address through which the questionnaires were received. We collected 356 returned online questionnaires. After excluding the respondents who were not using a VROLS (33) and questionnaires with invalid or repeated answers (27), the total number of valid questionnaires was 296, indicating a valid return rate of 83.1 percent. The valid responses included 136 females $(45.9 \%)$ and 160 $(54.1 \%)$ males. The highest proportion $(53.8 \%)$ were aged between 19 and 25;27.7\% were aged between 26 and $35,12.2 \%$ were under 18 , and $6.3 \%$ were aged 36 and over. The largest number of responses had experience with the language learning (61.7\%), $22.5 \%$ were learning about computer, $10.1 \%$ were simulationbased training, and $5.7 \%$ were others.

\section{Results}

5.1. Tests of the measurement assessment
The measurement model was further assessed for construct reliability and validity. Reliability and validity analysis used Cronbach's alpha, composite reliability (CR), and average variance extracted (AVE) (see Table 1). We first tested the reliability of the measures for each construct by examining the Cronbach's alpha. The Cronbach's alpha of each construct ranged from 0.84 to 0.93 , which exceeded the recommended level of 0.7 [35]. Then, we used three primary measures to evaluate the convergent validity of the instrument. (1) All indicator factor loadings must be higher than 0.5 [36], (2) CR must be 0.7 or higher, and (3) the AVE of each construct must be 0.5 or higher [37]. As shown in Table 1, the factor loading of every item in the model exceeded 0.7 . The CR of constructs ranged from 0.84 to 0.93 . The AVE ranged from 0.63 to 0.76 . Thus, all constructs in the model had good reliability and convergent validity.

\subsection{Tests of the structural model}

We conducted structural equation modelling analysis by using AMOS 21.0 to test the structural model. The model-fit indices for the structural model indicated a good model fit $\left(\chi^{2} / \mathrm{df}=2.42\right.$, GFI $=0.82$, $\mathrm{AGFI}=0.79, \mathrm{NFI}=0.86, \mathrm{CFI}=0.91$, and RMSEA $=$ 0.069). Figure 2 shows the standardized coefficients path, path significances, and variance explained $\left(\mathrm{R}^{2}\right)$ by each path.

All of our twelve hypotheses were supported by the AMOS structural model, lending overall support to our proposed model of intention to use VR online learning system. The results revealed that VR online learning behavior was predominantly determined by perceived value $(\beta=0.22, p<0.01)$ and flow experience $(\beta=0.67, p<0.001)$. Perceived value $(\beta=$ $0.36, p<0.001)$ were also discovered to have a significant positive association with flow experience. Thus, H1a, H1b, and $\mathrm{H} 2$ were supported. Spatial presence $(\beta=0.41, p<0.001)$ have significant positive association with enjoyment thus, H3a was supported. The results indicated that perceived value was significantly affected by spatial presence $(\beta=0.30, p<$ $0.001)$, enjoyment $(\beta=0.16, p<0.05)$, service compatibility $(\beta=0.15, p<0.05)$, complexity $(\beta=-$ $0.12, p<0.05)$, and visual fatigue $(\beta=-0.15, p<$ 0.05). Thus, H3b, H4a, H5, H6a, and $\mathrm{H} 7 \mathrm{a}$ were supported. In a similar manner, flow experience significantly affected by spatial presence $(\beta=0.25, \mathrm{p}<$ $0.001)$, enjoyment $(\beta=0.24, \mathrm{p}<0.001)$, complexity $(\beta$ $=-0.11, p<0.05)$, and visual fatigue $(\beta=-0.16, p<$ 0.01). Thus, $\mathrm{H} 3 \mathrm{c}, \mathrm{H} 4 \mathrm{~b}, \mathrm{H} 6 \mathrm{~b}$, and $\mathrm{H} 7 \mathrm{~b}$ were fully supported. The variance explained $\left(\mathrm{R}^{2}\right)$ of $\mathrm{VR}$ online learning system usage intention was $69 \%$, that of perceived value was $35 \%$, that of flow experience was $63 \%$, and that of enjoyment was $17 \%$ 
Table 1. Construct reliability, convergent validity, and discriminant validity coefficients.

\begin{tabular}{|c|c|c|c|c|c|c|c|c|c|c|c|}
\hline \multirow[t]{2}{*}{ Construct } & \multirow[t]{2}{*}{$\mathrm{CR}$} & \multirow[t]{2}{*}{ AVE } & \multirow[t]{2}{*}{ Alpha } & \multicolumn{8}{|c|}{ AVE and squared correlations } \\
\hline & & & & SP & EN & $\mathrm{SC}$ & $\mathrm{CP}$ & VF & PV & FE & UI \\
\hline SP & 0.90 & 0.63 & 0.90 & $\begin{array}{l}0.79 \\
\end{array}$ & & & & & & & \\
\hline EN & 0.85 & 0.66 & 0.85 & 0.35 & 0.81 & & & & & & \\
\hline $\mathrm{SC}$ & 0.84 & 0.64 & 0.84 & 0.43 & 0.22 & $\mathbf{0 . 8 0}$ & & & & & \\
\hline $\mathrm{CP}$ & 0.90 & 0.76 & 0.90 & -0.15 & -0.24 & -0.15 & 0.87 & & & & \\
\hline VF & 0.93 & 0.72 & 0.93 & -0.37 & -0.31 & -0.17 & 0.21 & 0.85 & & & \\
\hline PV & 0.91 & 0.71 & 0.91 & 0.46 & 0.35 & 0.34 & -0.25 & -0.35 & 0.84 & & \\
\hline FE & 0.90 & 0.69 & 0.90 & 0.54 & 0.50 & 0.38 & -0.32 & -0.47 & 0.61 & 0.83 & \\
\hline UI & 0.84 & 0.63 & 0.84 & 0.52 & 0.39 & 0.31 & -0.19 & -0.38 & 0.59 & 0.72 & 0.79 \\
\hline
\end{tabular}

Note: Spatial presence (SP); Enjoyment (EN); Service compatibility (SC); Complexity (CP); Visual fatigue (VF); Perceived value (PV); Flow experience (FE); Usage intention (UI). Diagonal elements (bold) are the square root of average variance extracted (AVE) between the constructs and their measures. Off-diagonal elements are correlations between constructs. For discriminant validity, diagonal elements (AVE) should be greater than off-diagonal elements.

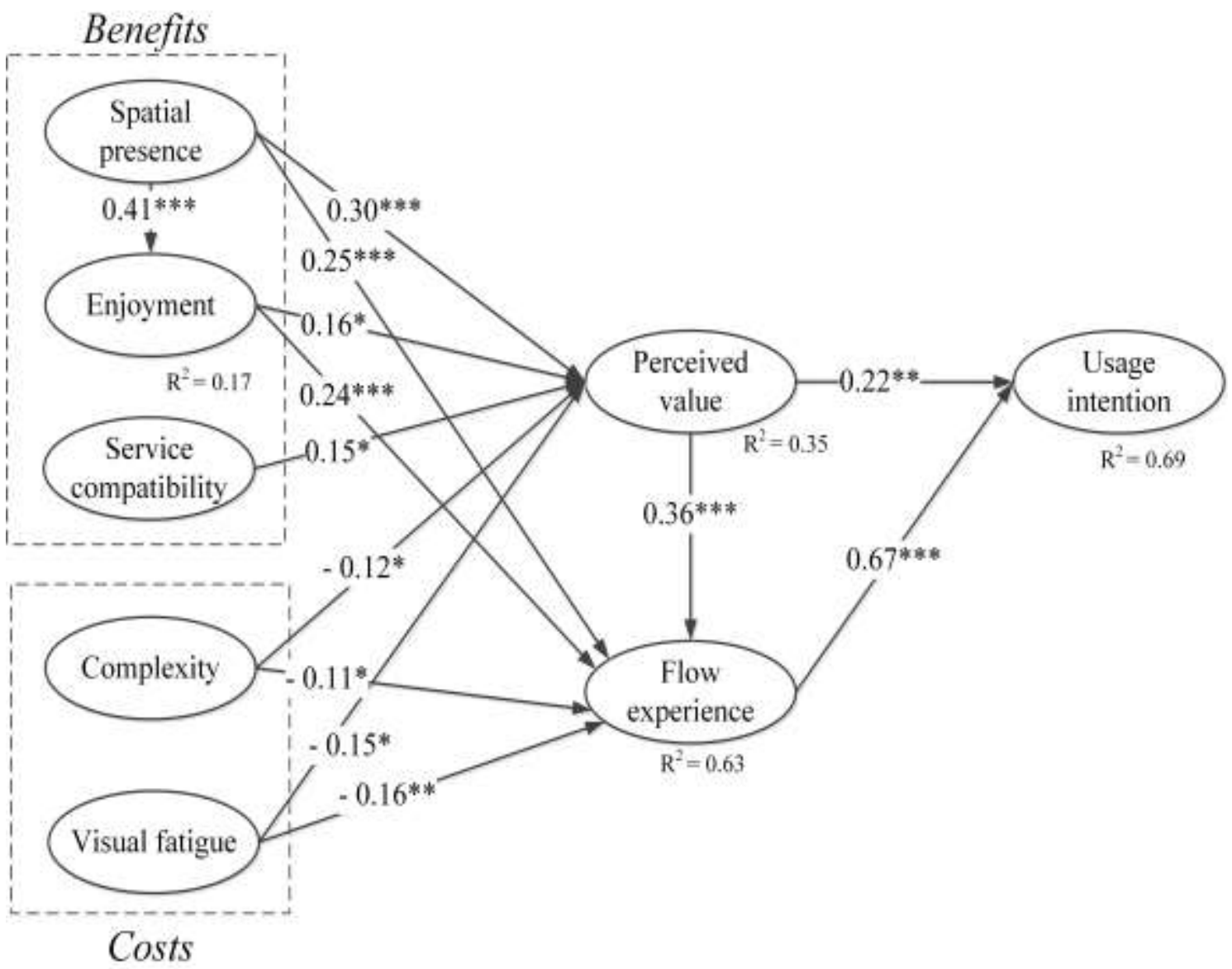

Figure 2. Structural model results (Note. ${ }^{* *} p<0.001,{ }^{* *} p<0.01,{ }^{*} p<0.05$ ) 


\section{Discussion and conclusions}

This study proposes an integrated research model, in the perspective of cost-benefit theory coupled with the perceived value and the flow theories, and having users of VR online learning as research subjects to identify the reasons why people use VR online learning systems. The findings are discussed below.

Figure 2 illustrates the research results regarding users. Our findings were that the major factors affecting users' use of VR online learning systems are perceived value and flow experience. The perceived value in particular has the most significant effect on such usage. According to our findings, which were consistent with those of other researchers [19][20], in a context of learning oriented information system, the flow experience is an important factor. Hence, for service providers of online learning system, the ability to increase VR-based curricular design does facilitate the learners to become completely committed to the online learning systems and the flow experience will help drive their behavior intention.

Secondly, perceived value significantly affects users' usage of VR online learning systems. It also significantly affects users' feeling of flow experience in such systems. Our findings also testified the views of other researchers [7][9][18] that when people have perceived value in such information technology, that positively affects their behavior intention. Also, when people consider such information technology of holistic value, they are in the state of flow experience, which in turn furthers their usage intention [14]. Our findings thus suggest that when the users have feeling of value for VR-based online learning systems, that positively affects their usage intention. It is indicated that in a context of VR application in learning, the new learning models that VR technology provides the users (e.g., vivid scenes, real-time visual feedback) can effectively enhance the users' feeling of holistic value during the learning, which in turn increases their usage intention during the learning.

Of the beneficial characteristics, spatial presence, enjoyment and service compatibility all directly and positively affect the perceived value and the flow experience. Also, spatial presence significantly affects users' enjoyable feeling about the VR-based online learning systems. The research by Tussyadiah et al. [22] discovered that the spatial presence which VR provides positively affects enjoyment, and in turn brings about feeling of value. Meantime, a number of researchers [11][20] found in their research that in VR contexts, spatial presence is a key factor directly affecting users' flow experience. Our findings showed that when the users consider when they learn via VR online learning, they feel as if acting in the real world and interacting in real time with the characters in the context, that gives the users' senses a spatial presence, which in turn enhances their feeling of VR value and facilitates their state of flow. Then, in enjoyment, our findings, consistent with those of other researchers [7][8], were that the enjoyment brought about by information technology positively affects users' perceived value. Furthermore, Kim and Hall [10] stated that in a VR context, enjoyment positively affected users' flow experience. Last, regarding service compatibility, our findings, consistent with those by Lin et al. [9] in exploring the usage behaviors of mobile technology, were that when users can use the service via VR technology just like in the learning modes they usually employ, that increases their feeling of perceived value.

In the cost-related characteristics, this study assumed that both complexity and visual fatigue negatively affect VR-based online learning systems. Regarding complexity, our findings suggested that if users felt the operations were easy during their online learning with VR technology, that increased their feeling of perceived value and brought about flow experience. It is thus clear that VR-based online learning providers should be highly aware of the design of neat operating interfaces, because if the users consider the system is easy to understand, they can make good use of provided services without efforts, which reduces their feeling of complexity of VR technology, and thus helps increase their feeling of value while helping them concentrate on and be committed to learning, before state of flow begins. On the other hand, prior research [26][27][28][29] indicated that when extended use of technological products causes visual fatigue in people, that would decrease their attitude toward the use of the same. Such view was verified by our findings, where if users have visual fatigue during their use of VR-based online learning, that negatively affects their feelings (perceived value and flow experience) and in turn decreases their usage intention. Hence, VR-based online learning providers should be more aware of the effect of visual fatigue in users, e.g., excessively likereal scenes or distances may bring about dizziness, eye fatigue and others [29]; the avoidance of the feeling of such visual fatigue would enhance the users' behavior of using VR-based online learning.

The results of this study have several important academic implications. First, this study proposed an integrated research model, based on the cost-benefit theory coupled with the perceived value and flow theories, for understanding what (positive and negative) cost and benefit attributes affect people's feeling of value and flow experience in VR-based online learning systems and further their usage intention. Second, this study incorporated the flow 
experience to more completely predict users' intention to use VR-based online learning services, as in prior research of how information technology affected, by value models, users' behaviors [5][6], the researchers recommended that besides the perspective of value, it is important to consider other affecting factors, where flow experience is a crucial factor for explaining and predicting users' behaviors of using information systems of learning contexts [19][20]. Third, in this study, in the perspective of perceived innovations characteristics, the perceived value brought about by VR-based online learning systems comprises the components of benefits and costs, in which the former include spatial presence, enjoyment and service compatibility and the latter include complexity and visual fatigue, and each of those factors affected the value perception for VR-based online learning services.

Several implications for mobile application service practitioners can be drawn from this study. First, users' usage intention of VR-based online learning systems is affected by both the factors of perceived value and of their flow experience. That indicates the need, in the design of teaching with VR, to be aware that the application of VR in the contexts and contents of online learning not only satisfies users' need for value but also draws them into flow experience in order to increase their usage intention. Second, our findings indicated that spatial presence is among the significant factors affecting perceived value and flow experience; hence, content designers should be more aware of the as-real learning environment that VR provides for the users, and by means of dynamic interactive visual feedbacks, making the users absorbed in as-real leaning environment and driving their usage intention. Third, this study further found that the constructs of spatial presence, enjoyment, service compatibility, complexity and visual fatigue are the important factors affecting individuals' VR-based online learning. Such result offers the practitioners important information that in the context of learning oriented information system, learners' spatial presence, enjoyment, service compatibility, complexity and visual fatigue in relation to VR-based online learning systems are a key reason affecting their perceived value and flow experience, and in turn their use of such service to learn.

\section{Limitations and future research}

Despite the valuable findings and implications, this study has some limitations. First, the implications were drawn from a single study with samples in Taiwan. Therefore, caution must be taken when generalizing the findings to other VR-based online learning system situations. Further research should be conducted in cross-cultural and cross-marketplace contexts to investigate and compare the differences in antecedents to use intention. Second, we employed a quantitative statistical research model and collected data by means of an online questionnaire; it is thus difficult for represented research sampling to avoid self-selection. We suggest that future studies use a qualitative assisted quantitative viewpoint to support their findings. Third, whilst the integrated research model hereof is used to explore learners' user intention for VROLS, it is recommended that future research also incorporate other theories (such as TAM) to develop other relevant variables and to examine the correlation between the variables. Fourth, the subjects of this study were simply learners; yet, in the educational environment, users of VR can be combinations of different groups of people (e.g., teachers or education institutions). It is recommended that the future research include surveys on more and different groups and further compare their use behaviors of VR for broader insight into why those groups use VROLS.

\section{Acknowledgments}

The authors thank the editor and anonymous reviewers for their comments and suggestions. This study was supported by a grant from the Ministry of Science and Technology: project number MOST-1092410-H-275-005, MOST-108-2410-H-275-005-.

\section{References}

[1] W. Wei, R. Qi, and Z. Lu, "Effects of virtual reality on theme park visitors' experience and behaviors: A presence perspective", Tourism Management, 71, 2019, pp.282-293.

[2] J.A Rupp, K.L. Odette, J. Kozachuk, J.R. Michaeli, J.A. Smither, and D.S. McConnell, "Investigating learning outcomes and subjective experiences in 360- degree videos", Computers \& Education, 128(1), 2019, pp. 256-268.

[3] D. Sportillo, A. Paljic, and L. Ojeda, "Get ready for automated driving using Virtual Reality", Accident Analysis and Prevention, 118(1), 2018, pp. 102-113.

[4] X. Zhang, S. Jiang, P. Ordóñez de Pablos, M.D. Lytras, and Y. Sun, "How virtual reality affects perceived learning effectiveness: a task-technology fit perspective", Behaviour \& Information Technology, 36(5), 2017, pp. 548-556.

[5] H.W. Kim, H.C. Chan, and S. Gupta, "Value-based adoption of mobile internet: An empirical investigation", Decision Support Systems, 43(1), 2007, pp. 111-126.

[6] K.Y. Lin, and H.P. Lu, "Predicting mobile social network acceptance based on mobile value and social influence", Internet Research, 25(1), 2015, pp. 107-130.

[7] Y.Y. Wang, H.H. Lin, Y.S. Wang, Y.W Shih, and S.T. Wang, "What drives users' intentions to purchase a GPS Navigation app: The moderating role of perceived availability of free substitutes", Internet Research, 27(1), 2018, pp. 251-274. 
[8] C.C. Chen, K.L. Hsiao, and S.J. Wu, "Purchase intention in social commerce: An empirical examination of perceived value and social awareness", Library Hi Tech, 36(4), 2018, pp. 583-604.

[9] K.Y. Lin, Y.T. Wang, and T.K. Hang, "Exploring the antecedents of mobile payment service usage: Perspectives from cost-benefit theory, perceived value, and social influences", Online Information Review, 44(1), 2020, pp. 299-318.

[10] M.J. Kim, and C.M. Hall, "A hedonic motivation model in virtual reality tourism: Comparing visitors and nonvisitors", International Journal of Information Management, 46, 2019, pp. 236-249.

[11] D. Kim, and Y.J. Ko, "The impact of virtual reality (VR) technology on sport spectators' flow experience and satisfaction", Computers in Human Behavior, 93, 2019, pp. 346-356.

[12] C.C. Chang, "Examining users' intention to continue using social network games: A flow experience perspective", Telematics and Informatics, 30(4), 2013, pp. 311-321.

[13] M. Csikszentmihalyi, Beyond boredom and anxiety, San Francisco: Jossey-Bass, 1975.

[14] M. Kim, and B. Thapa, "Perceived value and flow experience: Application in a nature-based tourism context", Journal of Destination Marketing \& Management, 8, 2018, pp. 373-384.

[15] R.N. Bolton, and J.H. Drew, "A multi-stage model of customer's assessments of service quality and value", Journal of Consumer Research, 17(4), 1991, pp. 375-384.

[16] M. Csikszentmihalyi, "The domain of creativity. In M. A. Runco \& R. S. Albert (Eds.)", Theories of creativity, Newbury Park: Sage, 1990.

[17]Y.P. Chang, and D.H. Zhu, "The role of perceived social capital and flow experience in building users' continuance intention to social networking sites in China", Computers in Human Behavior, 28(3), 2012, pp. 995-1001.

[18] C.C. Chen, and Y.C. Lin, "What drives live-stream usage intention? The perspectives of flow, entertainment, social interaction, and endorsement", Telematics and Informatics, 35, 2018, pp. 293-303.

[19] J. Fang, L.T. Tang, J. Yang, and M. Peng, "Social interaction in MOOCs: The mediating effects of immersive experience and psychological needs satisfaction", Telematics and Informatics, 39, 2019, pp. 75-91.

[20] I. Rodriguez-Ardura, and A. Meseguer-Artola, "Elearning continuance: The impact of interactivity and the mediating role of imagery, presence and flow", Information \& Management, 53(4), 2016, pp. 504-516.

[21] Rogers, E.M., Diffusion of Innovations. Fourth ed, New York: The Free Press, 1995.

[22] I.P Tussyadiah, D. Wang, T.H. Jung, and M.C. tom Dieck, "Virtual reality, presence, and attitude change: Empirical evidence from tourism", Tourism Management, 66, 2018, pp. 140-154.

[23] P.G.J. Hendriks Vettehen, D. Wiltink, M. Huiskamp, G.J. Schaap, and P.E. Ketelaar, "Taking the full view: How viewers respond to 360-degree video news", Computers in Human Behavior, 91, 2019, pp. 24-32.

[24] M. Lambooij, M. Fortuin, I. Heynderickx, and W. IJsselsteijn, "Visual discomfort and visual fatigue of stereoscopic displays: A review", Journal of Imaging Science and Technology, 53(3), 2009, pp. 30201-30214.

[25] I. Iatsun, M.-C. Larabi, and C. Fernandez-Maloigne, "Investigation and modeling of visual fatigue caused by S3D content using eye-tracking", Displays, 39(1), 2015, pp. 11-25. [26]C. Chen, J. Wang, K. Li, Y. Liu, and X. Chen, "Visual fatigue caused by watching 3DTV: an fMRI study", Biomedical engineering online, 14(1), 2015, pp. S12.

[27] Q. Wang, H. Xu, R. Gong, and J. Cai, "Investigation of visual fatigue under LED lighting based on reading task", Optik-International Journal for Light and Electron Optics, 126(15), 2015, pp. 1433-1438.

[28] S. Benedetto, A. Carbone, V. Drai-Zerbib, M. Pedrotti, and T. Baccino, "Effects of luminance and illuminance on visual fatigue and arousal during digital reading", Computers in Human Behavior, 41(1), 2014, pp. 112-119.

[29] J.A. Aznar-Casanova, A. Romeo, A.T. Gómez, and P.M. Enrile, "Visual fatigue while watching 3D stimuli from different positions", Journal of optometry, 10(3), 2017, pp. 149-160.

[30] J. Fang, Z. Zhao, C. Wen, and R. Wang, "Design and performance attributes driving mobile travel application engagement", International Journal of Information Management, 37(4), 2017, pp.269-283.

[31] D. Kim, and T. Ammeter, "Predicting personal information system adoption using an integrated diffusion model", Information \& Management, 51(4), 2014, pp. 451464.

[32] E.J. Cho, K.M. Lee, S.M. Cho, and Y.H. Choi "Effect of stereoscopic movies: The positions of stereoscopic objects and the viewing conditions", Displays, 35, 2014, pp. 59-65.

[33] Y.Y. Wang, Y.S. Wang, H.H. Lin, and T.H. Tsai, "Developing and validating a model for assessing paid mobile learning app success", Interactive Learning Environment, 27, 2019, pp. 458-477.

[34] A. Bhattacherjee, "An empirical analysis of the antecedents of electronic commerce service continuance", Decision Support Systems, 32(2), 2001, pp.201-214.

[35] C. Fornell, and D.F. Larcker, "Evaluating structural equation models with unobservable variables and measurement error", Journal of Marketing Research, 18(1), 1981, pp. 39-50.

[36] J. C. Nunnally, Psychometric Theory, McGraw Hill, New York, NY, 1978.

[37] C. Fornell, and D. F. Larcker, "Evaluating structural equation models with unobservable variables and measurement error", Journal of Marketing Research, 18(1), 1981, pp. 39-50. 